\title{
Correction to: Pelvic fat volume reduction with preoperative very low energy diet (VLED): implications for rectal cancer surgery in the obese
}

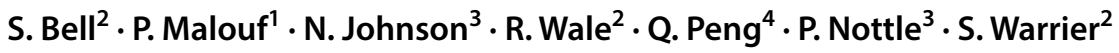

Published online: 26 September 2019

(c) Springer Nature Switzerland AG 2019

Correction to: Techniques in Coloproctology https://doi.org/10.1007/s10151-019-02074-y

Due to substantial contributions by Dr. Phillip Malouf and Dr. Stephen Bell, both authors are considered first authors of this article.

The original article can be found online at https://doi.org/10.1007/ s10151-019-02074-y.

\section{S. Bell}

SWBell@ccgroup.net.au

1 Department of Colorectal Surgery, Sutherland Hospital, University of New South Wales, Sydney, NSW, Australia

2 Cabrini-Monash University Department of Surgery, Cabrini Hospital, Suite 27 Cabrini Medical Centre, Isabella St, Malvern, VIC 3144, Australia

3 Department of Surgery, The Alfred Hospital, Melbourne, Australia

4 Department of Radiology, Montefiore Medical Center and Albert Einstein College of Medicine, Bronx, NY, USA 